\title{
Effectiveness of Peyton's four-step approach on nursing students' performance in skill-lab training
}

\author{
Shaimaa Ahmed Awad ${ }^{1}$, Madiha Hassan Nabih Mohamed*2 \\ ${ }^{1}$ Critical Care and Emergency, Faculty of Nursing, Mansoura University, Egypt \\ ${ }^{2}$ Medical Surgical Nursing, Faculty of Nursing, Mansoura University, Egypt
}

Received: October 19, 2018

DOI: $10.5430 /$ jnep.v9n5p1
Accepted: December 13, 2018 Online Published: December 29, 2018

URL: https://doi.org/10.5430/jnep.v9n5p1

\begin{abstract}
Objective: Conveying technical skills to students requires certain techniques and approaches. Peyton's four-step approach is a model that is becoming increasingly prevalent in medical education. This study was carried out to investigate the effectiveness of Peyton's four-step approach on nursing students' outcome in skill-lab training.

Methods: The current study was conducted at Faculty of Nursing, Mansoura University. A total of 80 students completed the study. The subjects were divided into two groups: Group (I) the intervention group composed of 40 students; 20 students from first level and 20 students from fourth level who received Peyton's four-step approach. Group (II) included 40 students considered as a control group composed of 20 students from first level and 20 students from fourth level who received the traditional method of lab training in our faculty. Two procedures were selected to be taught to the students; Intramuscular injection for first level students and arterial puncture for fourth level students.

Results: The studied groups significantly exceeded the control group in performance scoring in both intramuscular injection and arterial puncture procedures. The results of the current study also revealed that fourth level students show more acceptances and learning through Peyton's four-step approach than those of first level students.

Conclusions: In the light of the results of our study, we can emphasize that the use of Peyton's four-step approach as a model for teaching practical skills was helpful as reported by nursing students especially for fourth level students.
\end{abstract}

Key Words: Peyton's approach, Nursing students, Skill-lab training

\section{INTRODUCTION}

Skills-lab training, as a way of teaching, is considered an essential part of teaching programs in most of our healthrelated faculties. It offers a protected and mistake-forgiving training environment that permits students to practice skills on mannequins prior to actual skill performance on real patients. Furthermore, simulation-based education is proven to have a positive outcome in the clinical setting as it supports knowledge, skills and behavior domains so it improves knowledge, practical skills and communication of learners and allow them to accomplish practical skills faster, easier and in a more professional manner. ${ }^{[1,2]}$

The literature described several approaches used to convey technical skills; one of these methods is "Peyton's four-step approach". It is composed of 4 steps: first one is "Demonstrate"; in which the teacher carries out the skills without any explanations. Second step is "Talk the trainee through"; in which the teacher applies the corresponding procedure and clarifies each sub-step in details. Third step is "Trainee talks' trainer through"; in which the teacher accomplishes

*Correspondence: Madiha Hassan Nabih Mohamed; Email: Medicin483@yahoo.com; Address: Faculty of Nursing, Mansoura University, Egypt. 
the procedure for a third time. Fourth Step is "Trainee does"; in which the learner does the skills by himself/herself. ${ }^{[3,4]}$

Previously published studies have shown some advantages of Peyton's four-step approach in undergraduate medical education. ${ }^{4]}$ Although this approach was applied for small group medical students, to our knowledge, it was not applied on nursing students. As there is a growing need to develop teaching methods of nursing students and to prepare students for early exposure to clinical practice, this study was carried out to investigate the effectiveness of Peyton's fourstep approach on nursing students' performance in skill-lab training.

\section{MethodS}

A quasi experimental research design was used to achieve the aim of the current study. This current study was conducted at Faculty of Nursing, Mansoura University. Eighty students from first and fourth level were enrolled in the study. Students were divided into two groups: Group (I) the intervention group consisted of 40 students subdivided into 2 sub-groups; each sub-group contains 20 students from first level and 20 students from fourth level. Those 20 students split into 5 groups each contain 4 students who fulfill the inclusion criteria and who are eligible for the training sessions using Peyton's Four-Step Approach. Group (II) consisted of 40 students considered as a control group which is composed of 40 students subdivided into 2 sub-groups each sub-group contains 20 students from first level and 20 students from fourth level who received the traditional method of lab training in our faculty "see one, do one" technique. Inclusion criteria include first level and fourth level nursing students were willing to participate in the study. An exclusion criterion includes those who had previous experience of any of the selected procedures.

\subsection{Instrumentation}

Two tools were used in the current study: Tool I: Objective structured assessment of Intramuscular injection and arterial puncture checklists adopted from Athreya B, 2010 and Berman et al. (2016). ${ }^{[5,6]}$ They were used to assess the competence of the students in performing Intramuscular injection and arterial puncture procedures on a mannequin for both first and fourth level students respectively. Tool II: Acceptance rating scale of skill lab training sessions; this tool was adopted from Nikendei et al. (2014) ${ }^{[1]}$ to judge the participants' acceptance of the Peyton's four-step approach. Statements about the teaching modality were on a five-point likert scale in which 1 denotes completely disagree and 5 denotes completely agree.

\subsection{Study procedures}

An official written permission to conduct the study was obtained from the college dean and written informed consents were obtained from all enrolled students after explanation of the study aim. Students were reassured that the obtained data will be confidential and they have a right to withdraw from the study at any time without giving any reason. Two procedures were selected to be taught to the students; Intramuscular injections to be taught for first level students and arterial puncture to be taught for fourth level students as these skills represent a fundamental repetitive practice in nursing science. The study was completed over a period of one month along with the regular curriculum of our faculty.

The training sessions include 4 steps: Step one: the trainer performs skills without any details (Demonstration). Step two: the trainer provides instructions in detail (Deconstruction). Step three: the students must describe each sub-step whereas the instructor tracks the participant's instructions (Comprehension). Step four: the student performs the complete skill by himself on his own performance (Performance). To appraise Peyton's approach to small group training, an instructor completed one training session to every group, and Peyton's four-step approach was applied by the researchers to insure adherence to instructions.

To investigate effectiveness of training session on nursing students' performance, comparison was done between the intervention and control groups regarding their performance using the objective structured assessment checklist and their acceptance of the teaching model.

\subsection{Data analysis}

Statistics for all variables were calculated using SPSS version 21. The empirical distribution of continuous data was described as means and standard deviation. Intergroup differences between variables were assessed using the independent sample $t$ test. Comparison was made within a group using the dependent sample $t$ test. The level of significance in this study was $p<.05$.

\section{RESUlts}

This study included 80 nursing students in their first and fourth levels, sixty of them were females (75\%), and twenty were males $(25 \%)$; with mean age $19.5 \pm 1.5$ years.

Table 1 reflects mean performance score regarding intramuscular injection among first level students. It can be noticed that, students' competencies upgraded significantly over the course of the training and show a high statistically significant difference between study and control groups as study group presented a significantly independent performance of 
intramuscular injection compared to control group $(p=.000)$.

Table 2 shows mean performance score regarding arterial puncture procedure among fourth level students. It is clear that, intervention group exhibited a significantly independent performance of arterial puncture compared to control group $(p=.000)$.

Table 1. Mean performance score regarding Intramuscular (IM) injection among first level students

\begin{tabular}{|c|c|c|c|c|}
\hline & \multicolumn{2}{|l|}{ First level students } & \multirow{3}{*}{$t$} & \multirow{3}{*}{$p$} \\
\hline & Intervention group & Control group & & \\
\hline & Mean \pm SD & Mean \pm SD & & \\
\hline Performance score for IM injection & $22.57 \pm 1.33$ & $18.57 \pm 1.31$ & 9.578 & $.000^{*}$ \\
\hline
\end{tabular}

${ }^{*} p<.05 ;$ : independent sample $t$-test.

Table 3 shows a comparison between studied groups (first and fourth level study groups) regarding their procedure competencies. It appears from the table that both groups rated the overall skills as high but fourth level students showed significant increase in performance score than first level students $(p=.000)$.

Table 2. Mean performance score regarding arterial puncture (AP) among fourth level students

\begin{tabular}{llll}
\hline & \multicolumn{1}{l}{ Fourth level students } & & $\boldsymbol{t}$ \\
\cline { 2 - 3 } & Intervention group & Study group & $\boldsymbol{p}$ \\
\cline { 2 - 3 } & Mean \pm SD & Mean \pm SD & 7.013 \\
\hline Performance score For AP & $23.82 \pm 0.59$ & $21.45 \pm 1.39$ & $.000^{*}$ \\
\hline${ }^{*} p<.05 ; t$ : independent sample $t$-test. & & &
\end{tabular}

${ }^{*} p<.05$; $t$ : independent sample $t$-test.

Table 3. Comparison between studied groups (first and fourth level students) regarding mean difference of performance score

\begin{tabular}{|c|c|c|c|c|}
\hline & Groups & & & \\
\hline & First level & Fourth level & $t$ & $p$ \\
\hline & Mean \pm SD & Mean \pm SD & & \\
\hline Performance score & $22.57 \pm 1.33$ & $23.82 \pm 0.59$ & -3.84 & $.000 *$ \\
\hline
\end{tabular}

Figure 1 illustrates the students' acceptance rating of Peyton Four-Step Approach. Global ratings of acceptance of training of studied groups confirmed a high training acceptance after the skills training session had been finished in which acceptance was rated very high among the learners. Students were strongly agreed with the statement that they learned a lot during the training session (1st level group $4.75 \pm .444$, 4th level group $5.00 \pm .000, p=.016$ on a 5-point Likert Scale) and they were continuously alert during the training (1st level group $4.75 \pm .444$, 4th level group $5.00 \pm .000, p$ $=.016$ on A 5-point Likert Scale). They also acknowledged that repeated observations of the procedure were helpful (1st level group $4.75 \pm .444,4$ th level group $5.00 \pm .000, p=.016$ on A 5-point Likert Scale), and independent performance of the procedure was helpful (1st level group $4.75 \pm .444$, 4th level group $5.00 \pm 0.000, p=.016$ on A 5-point Likert Scale).

Published by Sciedu Press
Moreover, the majority of studied groups agreed that remarking weak points was beneficial (1st level group $4.25 \pm .444$, 4th level group $4.75 \pm 0.225, p=.016$ ) and they feel secure and well prepared for practicing the procedure independently after finishing the training (1st level group $4.75 \pm .444$, 4 th level group $5.00 \pm .000, p=.016$ ) with a more statistical significantly acceptance of our approach appears in 4th level studied group (all ratings are given as mean of Likert scale ratings from 5 = fully agree; 1 = completely disagree). On the other hand few number of students reported that there were too few repeated observations of the procedures, more noticed in first level students $(3.50 \pm 1.433)$ than fourth level students $(1.25 \pm 0.245)$, and there were fewer independent performances reported by first level students $(3.20 \pm 1.152)$ than fourth level students $(2.00 \pm 1.443)$.

\section{Discussion}

This study investigated the learning outcomes of the Peyton's four-step approach on nursing students' performance and their acceptance of the training sessions. It was found that the mean age of the students was $19.5 \pm 1.5$ years. With regards to gender, the majority of the sample was females. No significant difference was found between the intervention and control groups related to age and gender.

In the current study, the studied groups significantly outper- 
formed the control group in performance scoring in both intramuscular injection and arterial puncture procedures. This was shown in a previous report in which the authors demonstrate Peyton's four-step approach which result in quicker practical execution when compared to usual training "see one, do one". ${ }^{[4,7]}$ Also, this result was in line with Romero et al who applied Peyton's four step approach in teaching students a difficult laparoscopic skill. They found that Peyton's group outperformed Halsted's group in procedural scoring. ${ }^{[8]}$

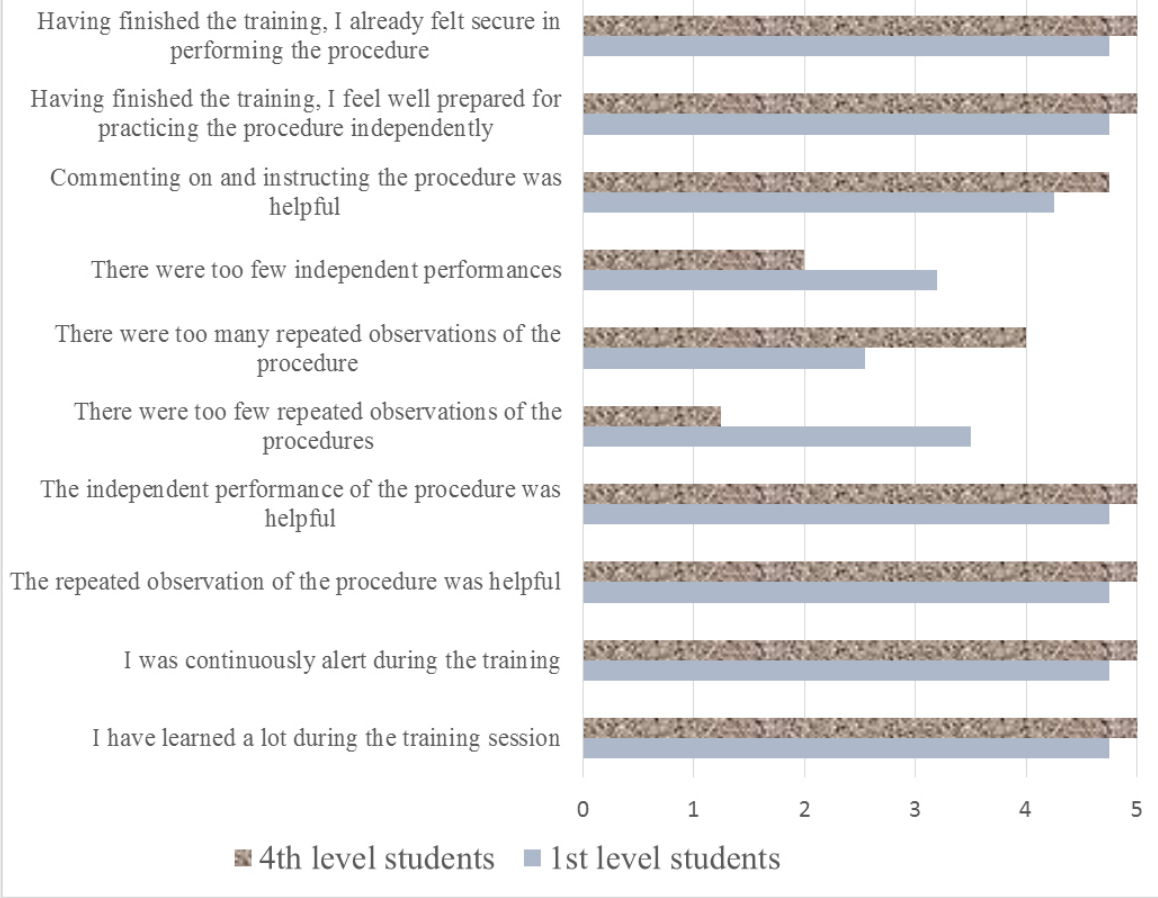

Figure 1. Student's acceptance ratings of skills-lab training session

Moreover, the results of the current study showed the practicability of the displayed approach. The approach was very much acknowledged via students and was evaluated as simple to learn resulting in attracting trainees' attention when observed by the teachers. The acceptance rating scale revealed that the trainees learned a lot during the training session, this result was in line with Moran et al. (2012) who stated that Peyton's four-step approach might be of critical importance for improving students' practical performance. ${ }^{[9]}$

This study assumed that the group of trainees who were instructed by Peyton's four-step approach was continuously alert throughout the training sessions. This was consistent with Shafizadeh et al. (2011), Kasper et al. (2012), and Jongbloed et al. (2012) who revealed that Peyton's four-step approach impacted motor skills attainment, including the focus of attention, visuospatial capabilities, execution perception, motor imagery, and practical memory limits. ${ }^{[10-12]}$

In addition, the majority of the studied groups appreciated the repeated observations of the procedures that allow inde- pendent performance and increase competencies. This was supported by Holmes et al 2008 and Moran et al. (2012) who stated that repetitions of steps were more efficient than procedure observation only..$^{[9,13]}$ It was supposed that frequent observations were of valued training for students for their own performance. ${ }^{[1]}$

In our study students confirmed that giving feedback during procedure demonstration was beneficial, in this respect, a study carried out by Nikendei et al. (2014) emphasized that giving comments had been recognized to be extremely appropriated and helped in improving learning outcome. Moreover, expression of comments increases student's alertness to exact technique. ${ }^{[1]}$

The present study's acceptance rating scale provided by students revealed that they feel well equipped for practicing the procedure autonomously after finishing the training. This was also demonstrated in a previous study, by Krautter 2011 who speculated that Peyton's four-step approach prompts a prevalent and quicker practical execution when participants 
demonstrated their first performance compared to a usual skill lab training method. ${ }^{[7]}$

The results of the current study also revealed that fourth level students showed more acceptance and learning through Peyton's four-step approach than those of first level students. This was in line with Lund 2012 who emphasized that active and standardized educational experiences are important factors that increase student's knowledge, skills, behavior and abilities to acquire clinical technical skills. ${ }^{[14]}$ Moreover, it prevents trainees from being passive bystander. ${ }^{[14]}$

\section{Limitations}

Some limitations of the present study must be declared. The circumstances in which this study carried out in terms of teacher-student ratio did not reproduce usual skill-lab training conditions. Moreover, the researchers didn't assess objective proficiencies of the procedures preceding the training session. This might have been predefined exclusion crite- rion for participants, considering our aim was to evaluate participants' first independent autonomous execution of the targeted skill. Finally, the duration of providing Peyton's approach was limited to only one month as we examined only 2 procedures. We suggest practicing this approach for more procedures and for longer periods of time in order to assess more accurately the ability of students to perform procedures after a long period of time.

\section{SUMmary}

In light of the results of our study, we can emphasize that the use of Peyton's four-step approach as a model for teaching practical skills was helpful as reported by nursing students especially for fourth level students.

\section{CONFlicts of InTEREST Disclosure}

The author declares that there is no conflict of interest statement.

\section{REFERENCES}

[1] Nikendei C, Huber J, Stiepak J, et al. Modification of peyton's fourstep approach for small group teaching: A descriptive study. BioMed Central Medical Education Journal. 2014; 14(1): 68.

[2] Bosse HM, Mohr J, Buss B, et al. The benefit of repetitive skills training and frequency of expert feedback in the early acquisition of procedural skills. BioMed Central Medical Education Journal. 2015; 15(1): 22.

[3] Benjamin L. Selection, teaching and training in ophthalmology. Clinical \& Experimental Ophthalmology Journal. 2005; 33(5): 524-530. PMid:16181283 https://doi.org/10.1111/j.1442-9071.20 05.01089.x

[4] Krautter M, Dittrich R, Safi A, et al. Peyton's four-step approach: differential effects of single instructional steps on procedural and memory performance: A clarification study. Advances in Medical Education and Practice Journal. 2015; 6: 399-406. PMid:26060417 https://doi.org/10.2147/AMEP.S81923

[5] Athreya BH. Handbook of Clinical Skills: A Practical Manual. World Scientific Publishing Co, Inc. 2010.

[6] Berman A, Shirlee J, Frandsen G. KOZIER \& ERB'S. Fundamentals of Nursing. Concepts, Process, and Practice. 10th ed. Pearson Education, Inc. USA. 2016.

[7] Krautter M, Weyrich P, Schultz JH, et al. Effects of peyton's four-step approach on objective performance measures in technical skills training: A controlled trial. Teaching and Learning in Medicine Journal. 2011; 23(3): 244-50. PMid:21745059 https://doi .org/10.108 $0 / 10401334.2011 .586917$

[8] Romero P, Günther P, Kowalewski KF, et al. Halsted's "see one, do one, and teach one" versus peyton's four-step approach: A randomized trial for training of laparoscopic suturing and knot tying. Jour- nal of Surgical Education. 2018; 75(2): 510-515. PMid:28801083 https://doi.org/10.1016/j.jsurg.2017.07.025

[9] Moran A, Guillot A, MacIntyre T, et al. Re-Imagining motor imagery: building bridges between cognitive neuroscience and sport psychology. British Journal of Psychology. 2012; 103(2): 224-247. PMid:22506748 https://doi .org/10.1111/j . 2044-8295. 20 $11.02068 . x$

[10] Kasper RW, Elliott JC, Giesbrecht B. Multiple measures of visual attention predict novice motor skill performance when attention is focused externally. Human Movement Science Journal. 2012; 31(5): 1161-1174. PMid:22516836 https://doi.org/10.1016/ j.humov. 2011.11.005

[11] Shafizadeh M, McMorri T, Sproule J. Effect of different external attention of focus instruction on learning of golf putting skill. Perceptual and Motor Skills Journal. 2011; 113(2): 662-670. PMid:22185080 https://doi.org/10.2466/05.23.25.PMS.1 13.5.662-670

[12] Jongbloed-Pereboom M, Janssen AJ, Steenbergen B, et al. Motor learning and working memory in children born preterm: A systematic review. Neuroscience \& Biobehavioral Reviews. 2012; 36(4): 1314 1330. PMid:22353425 https://doi.org/10.1016/j.neubiore v. 2012.02 .005

[13] Holmes P, Calmels C. A neuroscientific review of imagery and observation use in sport. Journal of Motor Behavior. 2008; 40(5): 433-445. PMid:18782718 https : //doi .org/10.3200/JMBR . 40. $5.433-445$

[14] Lund F, Schultz JH, Maatouk I, et al. Effectiveness of iv cannulation skills laboratory training and its transfer into clinical practice: A randomized, controlled trial. PLoS One Journal. 2012; 7: 32831. PMid:22427895 https://doi.org/10.1371/journal.pone.0 032831 